\title{
Antifungal and anti-biofilm activity of a new Spanish extract of propolis against Candida glabrata
}

\author{
María Coronada Fernández-Calderón 1,2,3*, Laura Hernández-González , Carolina Gómez-Navia', \\ María Teresa Blanco-Blanco ${ }^{1}$, Rosa Sánchez-Silos ${ }^{4}$, Leopoldo Lucio ${ }^{5}$ and Ciro Pérez-Giraldo 1,2,3
}

\begin{abstract}
Background: Resistance to traditional antifungal agents is a considerable health problem nowadays, aggravated by infectious processes related to biofilm formation, usually on implantable devices. Therefore, it is necessary to identify new antimicrobial molecules, such as natural products, to develop new therapeutic strategies to prevent and eradicate these infections. One promising product is propolis, a natural resin produced by honeybees with substances from various botanical sources, beeswax and salivary enzymes. The aim of this work was to study the effect of a new Spanish ethanolic extract of propolis (SEEP) on growth, cell surface hydrophobicity, adherence and biofilm formation of Candida glabrata, a yeast capable of achieving high levels of resistance to available anti-fungal agents.
\end{abstract}

Methods: The antifungal activity of SEEP was evaluated in the planktonic cells of 12 clinical isolates of C. glabrata. The minimum inhibitory concentration (MIC) of propolis was determined by quantifying visible growth inhibition by serial plate dilutions. The minimum fungicide concentration (MFC) was evaluated as the lowest concentration of propolis that produced a $95 \%$ decrease in $\mathrm{cfu} / \mathrm{mL}$, and is presented as $\mathrm{MFC}_{50}$ and MFC 90 , which corresponds to the minimum concentrations at which 50 and $90 \%$ of the C. glabrata isolates were inhibited, respectively. Influence on cell surface hydrophobicity (CSH) was determined by the method of microbial adhesion to hydrocarbons (MATH). The propolis effect on adhesion and biofilm formation was determined in microtiter plates by measurement of optical density (OD) and metabolic activity (XTT-assay) in the presence of sub-MIC concentrations of SEEP.

Results: SEEP had antifungal capacity against C. glabrata isolates, with a $\mathrm{MIC}_{50}$ of $0.2 \%(\mathrm{~V} / \mathrm{V})$ and an $\mathrm{MFC}_{50}$ of $0.4 \%$, even in azole-resistant strains. SEEP did not have a clear effect on surface hydrophobicity and adhesion, but an inhibitory effect on biofilm formation was observed at subinhibitory concentrations (0.1 and 0.05\%) with a significant decrease in biofilm metabolism.

\footnotetext{
* Correspondence: koferca@unex.es

Departamento de Ciencias Biomédicas, Área de Microbiología, Facultad de Medicina y Ciencias de la Salud, Universidad de Extremadura, Badajoz, Spain ${ }^{2}$ Centro de Investigación Biomédica en Red de Bioingeniería, Biomateriales y Nanomedicina (CIBER BBN), Badajoz, Spain

Full list of author information is available at the end of the article
}

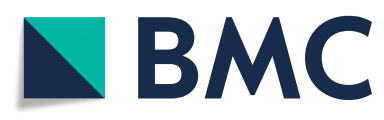

(c) The Author(s). 2021 Open Access This article is licensed under a Creative Commons Attribution 4.0 International License, which permits use, sharing, adaptation, distribution and reproduction in any medium or format, as long as you give appropriate credit to the original author(s) and the source, provide a link to the Creative Commons licence, and indicate if changes were made. The images or other third party material in this article are included in the article's Creative Commons licence, unless indicated otherwise in a credit line to the material. If material is not included in the article's Creative Commons licence and your intended use is not permitted by statutory regulation or exceeds the permitted use, you will need to obtain permission directly from the copyright holder. To view a copy of this licence, visit http://creativecommons.org/licenses/by/4.0/. The Creative Commons Public Domain Dedication waiver (http://creativecommons.org/publicdomain/zero/1.0/) applies to the data made available in this article, unless otherwise stated in a credit line to the data. 
Conclusions: The novel Spanish ethanolic extract of propolis shows antifungal activity against C. glabrata, and decreases biofilm formation. These results suggest its possible use in the control of fungal infections associated with biofilms.

Keywords: Candida glabrata, Propolis, Antifungal activity, Biofilm

\section{Background}

The frequency and diversity of fungal infections has changed in recent years, with a greater incidence of the opportunistic candida species; this is mainly due to increased immune-depressed patients, and to limitations of efficient antifungal agents [1]. Candida glabrata is a human commensal species which is present, among other places, in the digestive tube and with $15-50 \%$ of carriers [2-4]. Currently it is considered an emergent opportunistic pathogen in hospitalized patients, with a high incidence in Candida spp. isolates, behind only Candida albicans and sometimes Candida parapsilosis $[5,6]$. Pathogenicity of C. glabrata is related with determined virulence factors such as adhesion capacity and subsequent biofilm formation [7]. There exists a direct relation between the hydrophobic characteristics of the cellular wall of the yeasts and their adherence capacity. Hydrophobicity occurs when the yeast is not capable of interacting with the water molecules, either by iondipole interactions or by hydrogen bonds; the degree of intervention of the hydrophobic interactions depends on the characteristics of both the fungus and the surface [8]. Adhesion is the first step in the colonization and invasion of the tissues. The adhesion capacity prevents the yeast from being dragged and allowed to develop a biofilm which protects them from adverse conditions, favours their survival, and allows access to the blood stream and to the patient's internal organs.

Biofilms are clusters of viable and non-viable microorganisms which accumulate in a liquid-solid interface, embedded in a mucilaginous matrix composed of polymeric extracellular substances attached to a surface [9]; the matrix provides protection for the micro-organisms through concentrations of nutrients, impeding the access of biocides, oxidants, antibiotics, metallic cations and toxins. Thus biofilms play a fundamental role in infections related with implanted medical devices such as catheters, and dental, urinary or cardiac prostheses [10]. Infections by biofilm-forming fungi are more difficult to eradicate and Candida spp. has been associated with biofilm-related infections [11]. C. glabrata is capable of colonizing mucous surfaces and medical biodevices, and presents resistance to frequently used antifungals [4]. There is an urgent need, therefore, to find new therapeutic strategies with possible candidate products, preferably natural, for their use in the prevention and control of this type of infections; the development of new drugs from natural compounds for control of biofilm-related infections, which present fewer side effects, is at present receiving much attention $[9,12,13]$.

Propolis is a natural non-toxic product obtained from bee-hives, and is used by bees for the construction and restoration of the honeycomb [14]. It has antimicrobial, anti-inflammatory, anti-oxidant, immune-modulating and anti-tumour activity; it is therefore a product of great interest for the development of new medicines [15]. In recent years several studies have shown the antibacterial and antifungal effects of propolis, with variations according to its different origins [16-18], but few studies have been performed on clinical isolates of C. glabrata [19-21]. In previously published works we have verified the excellent antibacterial activity of the novel Spanish Ethanolic Extract of Propolis (SEEP) [22] and its foreseeable initial mechanism of action against gram-negative and grampositive bacteria [23]. The chemical profile of SEEP was determined by Liquid chromatography-mass spectrometry (LC-MS) and high-resolution gas chromatography coupled with mass spectrometry (GC-MS), and revealed for the first time the presence of olive oil compounds (Vanillic acid, 1-Acetoxypinoresinol, p-HPEA-EA and 3,4DHPEA-EDA). In addition, it should be noted that it contains high amounts of polyphenols (205 $\pm 34 \mathrm{mg} \mathrm{GAE} / \mathrm{g}$ ), with unusually more than half of these from the flavonoid class $(127 \pm 19 \mathrm{mg} \mathrm{QE} / \mathrm{g}$ ). The TFC/TPC ratio (total flavonoids content/total polyphenols contents) $(\sim 0.6)$ was the highest ever reported, both in Spain and in many parts of the world [22].

Thus, the aim of this study was to evaluate the usefulness of SEEP in the control of biodevice-associated infections caused by C. glabrata. To do so, we assessed its antifungal activity in clinical isolates of C. glabrata, and we analysed its ability to prevent biofilm formation and its effect on pathogenic yeast factors, biofilm-related, such as hydrophobicity, and adherence capacity.

\section{Methods}

\section{Strains and culture conditions}

Twelve C. glabrata strains, isolated from different patients and of different origins, seven from hemoculture $(12,20,30,42,45,52$ and 62$)$, one vaginal (64), one from sputum (63), two exudates $(60,61)$, and one from sample preservation liquid (65) at a tertiary care hospital (Hospital Universitario de Badajoz, Spain) were included in this study. The isolated C. glabrata strains were sent 
to us anonymized, in accordance with the protocol approved by the Ethical Committee of the Hospital, (Comité de Ética de la Investigación Clínica del CHUB), in order to maintain the confidentiality of the patients, and were included in our collection (MicromedBA). The clinical isolates were identified by sowing in chromogenic medium CHROMagar Candida ${ }^{\circ}$ and with biochemical methods using the API Candida ID32C system (bioMèrieux, Marcy L'Étoile, France). Sensitivity to antifungals was assessed by means of the automatic system Sensititre YeastOneR (Trek Diagnostic Systems, United Kingdom). Yeasts were conserved in vials at $-80^{\circ} \mathrm{C}$ (Microbanc, Prolab, Ontario, Canada). Later, the strains were cultivated on Sabouraud agar plates (OXOID LTD., Basingstoke, Hampshire, UK) and incubated at $37^{\circ} \mathrm{C}$ for $24 \mathrm{~h}$; two subcultures were made in RPMI-1640 (Sigma, St. Louis, MO, USA.) medium supplemented with $2 \%$ glucose, and at pH 7 in MOPS buffer (Sigma) for the different experiments.

\section{Propolis samples preparation}

The samples of propolis employed for analysis were from a new SEEP in $70 \%$ alcohol $(\mathrm{v} / \mathrm{v})$. The propolis was collected in the southwest of Spain and provided by "La Virgen de Extremadura" (Herrera del Duque, Badajoz, Extremadura, Spain). The SEEP was filtered as received with a $0.20 \mu \mathrm{m}$ syringe filter (Millipore, Merck, Darmstandt, Germany) and stored at $4{ }^{\circ} \mathrm{C}$ until use. This stock of SEEP, $100 \%(\mathrm{v} / \mathrm{v})$ is equivalent to $61.5 \mathrm{~g} / \mathrm{L}$ dry weight of propolis [22],

\section{Antifungal activity of SEEP on planktonic cells}

In this work we studied the in vitro antifungal effect of SEEP against planktonic C. glabrata. For the experimental assay, serial dilutions were performed and the effect of concentrations ranging from $0.8 \%$ of SEEP (equivalent to $480 \mu \mathrm{g} / \mathrm{mL}$ ) to $0.05 \%$ (eq. $30 \mu \mathrm{g} / \mathrm{mL}$ ) were studied.

The minimum inhibitory concentration (MIC) of the propolis extract was determined using agar dilution method [24] on 12 C. glabrata strains. Activity of the extract was evaluated by determining the minimum dilution which inhibited visible growth of C. glabrata on the plates. The following protocol was used: Serial dilutions of propolis extract were prepared on $70 \%$ alcohol and were incorporated to RPMI-1640 medium with agar at $1.5 \%$, to obtain concentrations from 0.8 to $0.05 \%$ with a maximum of $0.2 \%$ alcohol, and transferred to Petri plates. A standardized suspension of yeasts, prepared in RPMI-1640 at a concentration of $10^{4} \mathrm{cfu} / \mathrm{ml}$, taken from an overnight culture, was inoculated with a drop of $10 \mu \mathrm{L}$, deposited on the surface. In each plate 5-7 strains were inoculated, starting with those with the lowest concentration, and left to dry at room temperature. Control plates were used, one without propolis and the other with the alcohol used as a solvent. The plates were incubated for $24 \mathrm{~h}$ at $37{ }^{\circ} \mathrm{C}$ and were read visually; MIC was defined as the lowest propolis concentration which produced visible inhibition of yeast growth. The results are presented as Range, $\mathrm{MIC}_{50}$ and $\mathrm{MIC}_{90}$. The $\mathrm{MIC}_{50}$ value corresponds to the minimum concentration that inhibits at least $50 \%$ of the strains studied. The $\mathrm{MIC}_{90}$ value corresponds to the minimum concentration that inhibits $90 \%$ of the C. glabrata strains.

The minimum fungicidal concentration (MFC) of propolis was evaluated by dilution in liquid medium in 96-well microplates, using methodology M27-A4 of the CLSI [25] with minor modifications. Briefly, $100 \mu \mathrm{l}$ of RPMI-1640 with concentrations of SEEP of 1.6 to $0.1 \%$ (eq. 960 to $60 \mathrm{mg}$ dry weight of propolis) was transferred into the 96-well microplates (Greiner Bio-One $\mathrm{GmbH}$, Frickenhausen, Germany); next, $100 \mu \mathrm{l}$ of a suspension of yeasts (approximately $10^{4} \mathrm{cfu} / \mathrm{mL}$ ) was added, and final dilutions of SEEP from 0.8 to $0.05 \%$ were obtained. The microplates were incubated for $24 \mathrm{~h}$ at $37^{\circ} \mathrm{C}$. Subsequently, minimum fungicidal concentrations were determined according to the method of Gucwa et al., [26] with minor modifications. Aliquots of $10 \mu \mathrm{l}$ were taken from the different wells, starting from the MIC value, and were cultivated on plates of Sabouraud agar (OXOID LTD., Basingstoke, Hampshire, UK), and incubated for $24 \mathrm{~h}$ at $37^{\circ} \mathrm{C}$. The MFC was considered as the lowest SEEP concentration at which any colonies were observed. The results are presented as $\mathrm{MFC}_{50}$ and $\mathrm{MFC}_{90}$, these values corresponding to the minimum concentration at which 50 and $90 \%$ of the C. glabrata isolates were inhibited, respectively. All the evaluations were carried out in triplicate and on different days.

The inhibitory effect of SEEP on the growth kinetics of C. glabrata was studied $[27,28]$ by making a growth curve of C. glabrata strain 60 from shake flasks at $37^{\circ} \mathrm{C}$, with $50 \mathrm{ml}$ of RPMI- 1640 medium in the presence of $0.2 \%$ propolis and in control cultures without propolis and with $0.2 \%$ ethanol as solvent. The inoculum was prepared from a previous culture in RPMI-1640. Samples were taken every $2 \mathrm{~h}$; their OD was measured at $492 \mathrm{~nm}$ until the stationary phase was reached, finalizing at $80 \mathrm{~h}$ of incubation. The growth specific constant $(\mu)$ was measured according to the average slope during the exponential phase.

\section{Effect of propolis on virulence factors of $C$. glabrata}

The effect of SEEP on biofilm-forming capacity of $C$. glabrata was evaluated, as well as its effect on certain virulence factors such as adherence capacity and cell surface hydrophobicity (CSH).

\section{Influence on biofilm-forming capacity}

The effect of SEEP on biofilm-formation of C. glabrata in the presence of subinhibitory concentrations of 
propolis was studied (0.1 and 0.05\%). Flat-bottomed 96well polystyrene microtiter plates (Greiner Bio-One $\mathrm{GmbH}$, Frickenhausen, Germany) were used for this, following the method of Ramage et al. [29] with modifications [30]. Briefly, wells of plates were filled with $100 \mu \mathrm{l}$ of RPMI-1640 and SEEP, in quadruplicate, so that by adding $100 \mu \mathrm{l}$ of the inoculum to each well $\left(10^{6} \mathrm{cfu} / \mathrm{ml}\right.$ in RPMI-1640 medium), the concentrations of propolis to be studied were obtained $(0.1,0.05 \%)$. The microtiter plates were incubated for $24 \mathrm{~h}$ at $37^{\circ} \mathrm{C}$ with shaking, and then the plates were washed twice with cold PBS to remove the planktonic cells. The biofilm formed was evaluated by quantifying its mitochondrial metabolic activity, using the colorimetric method by reduction of XTT (Sigma, St. Louis, MO, USA.) described by Ramage et al. [29] . Aliquots of $100 \mu \mathrm{l}$ of XTT-menadione $(0,5 \mathrm{~g} / \mathrm{l}$ XTT, $1 \mu \mathrm{M}$ menadione) were added to the wells once washed, incubated for $1 \mathrm{~h}$ in the dark, and the colour formed was read at $490 \mathrm{~nm}$. Replicates were used to obtain representative images in the inverted microscope Leica DMi8 (Leica Microsystems GmbH, Wetzlar, Germany.). A control was made without propolis and another with the solvent. Each experiment was carried out in quadruplicate and repeated on three different times.

\section{Adherence capacity}

Adherence capacity to polystyrene was evaluated according to Christensen's technique with modifications, described previously by Galán-Ladero et al. [31]. Standardized suspension of yeasts with $\mathrm{OD}_{492}$ of 0.4 in PBS, were placed in 96-well $(0.25 \mathrm{ml} /$ well $)$ polystyrene flat-bottomed microtiter plates (Greiner bio-one $\mathrm{GmbH}$, Frickenhausen, Germany) in quadruplicate. Previously the yeast had been incubated $24 \mathrm{~h}$ at $37^{\circ} \mathrm{C}$ in RPMI1640 in the presence of subinhibitory concentrations of SEEP (0.1, 0.05\%); after several washes, suspensions were prepared and the microtiter plates filled. After $24 \mathrm{~h}$ at $37^{\circ} \mathrm{C}$ in a humid atmosphere with shaking, the suspensions were then aspirated and washed twice with cold PBS to remove non-adhering cells. A control was made without propolis and another with the solvent. The adhered layer of the wells was determined by measuring the OD at $492 \mathrm{~nm}$ on Universal Microplate Reader (ELx800; Bio-Tek Instruments, Inc. Winooski, VT, USA). It was considered adherent when an $\mathrm{OD} \geq 0.05$ was obtained.

\section{Cell surface hydrophobicity (CSH)}

The effect of SEEP on the CSH of C. glabrata strains was studied after incubation of the yeasts in RPMI 1640 in the presence of subinhibitory concentrations of propolis $(0.1$ and $0.05 \%)$ for $24 \mathrm{~h}$ at $37^{\circ} \mathrm{C}$. CSH levels were measured by the microbial adhesion to hydrocarbons
(MATH) test, using a modification of Rosenberg's biphasic water-hydrocarbon method [32] described by Galán-Ladero et al. [31]. Concretely, the yeast cells grown in tubes with $5 \mathrm{ml}$ of RPMI-1640 with shaking for $24 \mathrm{~h}$ at $37^{\circ} \mathrm{C}$ were harvested and washed twice with PBS $0.15 \mathrm{M}$ pH 7.2 cold PBS. The washed yeasts were resuspended in PBS until an OD of 0.4 to $492 \mathrm{~nm}$. To each 3 $\mathrm{ml}$ of suspension, $1 \mathrm{ml}$ of xylene (Panreac Química SAU, Barcelona, Spain.) was added, mixed by vortexing for 1 min, and incubated until the complete separation of the two phases occurred. Two controls were made without propolis and with the solvent. The absorbance (OD) of the aqueous phase was measured and the CHS was expressed as the percentage of reduction of the initial turbidity of the aqueous phase, and classified in accordance with the criteria described by Galán-Ladero et al. [31]: < 25\% low; 25-50\% medium; > 50\% high hydrophobicity. All the experiments were carried out in triplicate.

\section{Statistical methods}

All data were obtained from three independent experiments at least in duplicate for each strain. The results of propolis activity on adherence, CSH and biofilm formation were processed statistically by analysis of variance (one-way ANOVA) with the statistical program SPSS v22 (Chicago, Illinois, USA). Once the samples were found to be normal (Shapiro-wilk normality test), Dunnett's T3 test was performed if the variances were different, or by the HSD test if they were the same. Significant differences $(p<0.05)$ when compared with the control group were determined.

\section{Results}

\section{Antifungal activity of propolis in planktonic cells}

The initial characterisation of the strains was carried out according to susceptibility to conventional antifungal agents. A high percentage of the 12 strains of C. glabrata presented resistance or were sensitive dosedependent (SDD) to fluconazol with an $\mathrm{MIC}_{50}$ of $32 \mu \mathrm{g} /$ $\mathrm{mL}$; most were sensitive to voriconazol $\left(10 / 12, \mathrm{MC}_{50}\right.$ $0.5 \mu \mathrm{g} / \mathrm{mL})$, and to caspofungin and amphotericin B (11/ $12, \mathrm{MIC}_{50} 0.06 \mu \mathrm{g} / \mathrm{mL}$ ). Two strains isolated from haemoculture, strains 12 and 30, were resistant to voriconazol, strain 30 also being resistant to caspofungin and amphotericin B (Table 1). Then, antifungal activity of propolis on planktonic cells of C. glabrata was studied. MICs were evaluated by the technique of dilution in agar, which turned out to be a good method since the turbidity of the propolis dilutions made turbidimetric readings difficult in a liquid medium. The data relating to the MICs of SEEP are shown in Table 1, and include ranges and concentrations which inhibited $50 \%$ of the strains $\left(\mathrm{MIC}_{50}\right)$ and $90 \%$ of the strains $\left(\mathrm{MIC}_{90}\right)$. 
Table 1 Susceptibility of C. glabrata strains to several antifungal agents evaluated by Sensititre YeastOne and to propolis evaluated by agar dilution ( $\mathrm{MIC}$ in $\mu \mathrm{g} / \mathrm{mL}$ )

\begin{tabular}{llll}
\hline Antifungal Agents & Range & MIC $_{\mathbf{5 0}}$ & $\mathbf{M I C}_{\mathbf{9 0}}$ \\
\hline Fluconazole & $1-256$ & 32 & 128 \\
Voriconazole & $0.06-2.00$ & 0.5 & 2.00 \\
Caspofungin & $0.06-0.250$ & 0.06 & 0.125 \\
Amphotericin B & $0.25-2.00$ & 1.00 & 2.00 \\
Propolis & $60-240$ & 120 & 120 \\
\hline
\end{tabular}

$\mathbf{M I C}_{\mathbf{5 0}}$ : minimum concentration that inhibits $50 \%$ of the strains

MIC $_{90}$ : minimum concentration that inhibits $90 \%$ of the strains

All the twelve strains of C. glabrata studied were very sensitive in vitro to SEEP. The propolis extract had good antifungal activity, with MIC values within the range of $0.1-0.4 \%(60-240 \mu \mathrm{g} / \mathrm{mL})$, with a $\mathrm{MIC}_{50}$ and a $\mathrm{MIC}_{90}$ of $0.2 \%(120 \mu \mathrm{g} / \mathrm{mL})$. SEEP exhibited excellent fungicidal activity against isolates of $C$. glabrata, with an $\mathrm{MFC}_{50}$ of $0.4 \%(240 \mu \mathrm{g} / \mathrm{mL})$, an $\mathrm{MFC}_{90}$ of $0.8 \%(480 \mu \mathrm{g} / \mathrm{mL})$ and range $0.4->1.5 \%$. Strain 30 isolated from haemoculture was multi-resistant to antifungal agents (fluconazole, voriconazole, amphotericin B and caspofungin), and was sensitive to propolis, with a MIC of $0.2 \%(120 \mu \mathrm{g} / \mathrm{mL})$ and an MFC of $0.8 \%(480 \mu \mathrm{g} / \mathrm{mL})$. Strain 12, which was isolated from haemoculture and was resistant to the azoles tested, presented fungistatic but not fungicidal activity at the concentrations studied (MIC of $0.2 \%$ and MFC > 1.5\%).

Growth kinetics of C. glabrata was studied in strain 60 , isolated from exudates. A growth curve in RPMI1640 medium, according to OD values, in the presence of SEEP at $0.2 \%$ was studied. Flasks with $50 \mathrm{ml}$ of RPMI1640 at $0.2 \%$ propolis, were inoculated with $0.5 \mathrm{ml}$ of yeast grown in RPMI-1640 from $24 \mathrm{~h}$ subculture. Growth curves in the absence of propolis and with $0.2 \%$ ethanol as solvent control were made. The growth curve with lag phase, exponential growth phase and stationary phase of the C. glabrata strain 60 is observed in Fig. 1. The presence of $0.2 \%$ of propolis produces a lag phase of $32 \mathrm{~h}$, as observed in Fig. 1, which is much higher than the $5 \mathrm{~h}$ lag phase presented by the control free of propolis and the control with solvent. From this point on, the exponential phase occurs with a $\mu$ of $0.03 \mathrm{~h}^{-1}$, lower than that of the two controls, without propolis and the solvent control, which was $0.09 \mathrm{~h}^{-1}\left(\mathrm{R}^{2}=0.98\right)$, thus demonstrating the inhibitory effect in propolis growth at $0.2 \%(P<0.05)$. The stationary phase was reached after $54 \mathrm{~h}$ of culture with a maximum biomass (0.58 OD) much lower than that of the controls (1.56 OD). The control free of propolis and the solvent control had similar behaviour in all the phases.

\section{Effects of propolis on C. glabrata virulence factors}

The effect of SEEP at subinhibitory concentrations $(0.05$ and $0.1 \%$ ) on $\mathrm{CSH}$, adherence capacity, and biofilmformation is shown in Table 2. The CSH of the yeast was measured during the early stationary phase of growth. The $\mathrm{CSH}$ of the strains was classified according to the criteria described by Galán-Ladero et al. [31] with the following rankings: <25\%, low; $25-50 \%$, medium, and $>50 \%$, high. All C. glabrata isolates were hydrophobic, with average CSH of $66.0 \pm 27$. However, the strains studied were divided into two groups, 7 strains being highly hydrophobic (>50\%) with a mean CSH value of $85.9 \% \pm 12.4$, and 5 strains presented a medium hydrophobicity with values of $38, .0 \% \pm 7,3)$. No modifications produced by propolis were observed for any of the groups in $\mathrm{CSH}$. The $\mathrm{CSH}$ of the strains increased in the solvent control $(69.97 \% \pm 29)$ compared to the propolisfree control $(66.0 \pm 27)$, which had a value similar to that obtained in the presence of $0.05 \%$ of propolis $(71.01 \pm$ 25). The presence of $0.1 \%$ SEEP reduced to $63.9 \%$ the

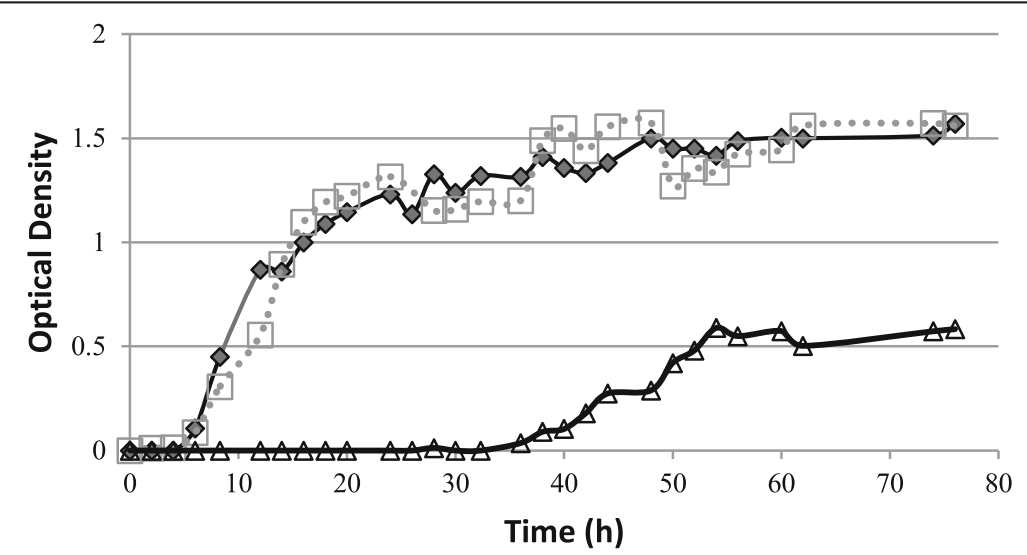

Fig. 1 Kinetics of growth of C. glabrata strain 60, in RPMI-1640 medium with a concentration of propolis of $0.2 \%(\Delta)$, and controls free of propolis ( ) and with $0.2 \%$ solvent ( $\square$ ). Optical Density of culture during $80 \mathrm{~h}$ of incubation at $35^{\circ} \mathrm{C}$ in flask with shaking 
Table 2 Effect of propolis at subinhibitory concentrations (0.05 and 0.1\%) on CSH, adherence capacity and biofilm formation of C. glabrata $(n=12)$

\begin{tabular}{|c|c|c|c|c|c|c|c|c|c|}
\hline \multirow{2}{*}{$\begin{array}{l}\text { Candida glabrata strains } \\
\text { High CSH (Origin) }\end{array}$} & \multicolumn{3}{|l|}{ CSH (\%) } & \multicolumn{3}{|c|}{ Adherence (OD) } & \multicolumn{3}{|c|}{ Biofilm (XTT-OD) } \\
\hline & Control & $0.05 \%$ & $0.10 \%$ & Control & $0.05 \%$ & $0.10 \%$ & Control & $0.05 \%$ & $0.10 \%$ \\
\hline $12(H)$ & 89.2 & 80.3 & 64.5 & 0.09 & 0.10 & 0.10 & 0.38 & 0.31 & 0.29 \\
\hline $20(H)$ & 89.7 & 80.6 & 55.7 & 0.15 & 0.11 & 0.10 & 0.70 & 0.55 & 0.45 \\
\hline $45(H)$ & 96.0 & 97.3 & 96.2 & 0.13 & 0.10 & 0.11 & 0.61 & 0.40 & 0.31 \\
\hline $60(\mathrm{E})$ & 91.6 & 100.0 & 100.0 & 0.13 & 0.10 & 0.10 & 0.65 & 0.51 & 0,50 \\
\hline $61(\mathrm{E})$ & 79.3 & 96.2 & 97.7 & 0.12 & 0.10 & 0.09 & - & - & - \\
\hline $63(S)$ & 60.7 & 73.7 & 63.2 & 0.13 & 0.06 & 0.08 & 0.50 & 0.40 & 0.31 \\
\hline $65(P)$ & 94.8 & 93.7 & 83.3 & 0.13 & 0.13 & 0.08 & - & - & - \\
\hline Median \pm SD & $85.9 \pm 12.4$ & $88.8 \pm 10.4$ & $80.1 \pm 18.7$ & $0.13 \pm 0.02$ & $0.10 \pm 0.02$ & $0.09 \pm 0.01$ & $0.57 \pm 0.13$ & $0.43 \pm 0.10$ & $0.37 \pm 0.10$ \\
\hline Medium CSH (Origin) & Control & $0.05 \%$ & $0.10 \%$ & Control & $0.05 \%$ & $0.10 \%$ & Control & $0.05 \%$ & $0.10 \%$ \\
\hline $30(H)$ & 45.2 & 41.7 & 40.0 & 0.14 & 0.10 & 0.11 & 0.71 & 0.51 & 0.40 \\
\hline $42(H)$ & 36.9 & 42.6 & 23.0 & 0.12 & 0.24 & 0.17 & 0.60 & 0.36 & 0.34 \\
\hline $52(H)$ & 41.5 & 36.5 & 53.0 & 0.14 & 0.09 & 0.09 & 0.56 & 0.39 & 0.38 \\
\hline $62(H)$ & 40.4 & 73.1 & 47.3 & 0.11 & 0.10 & 0.10 & 0.70 & 0.40 & 0.38 \\
\hline $64(V)$ & 26.2 & 36.4 & 42.6 & 0.15 & 0.10 & 0.10 & - & - & - \\
\hline Median \pm SD & $38.0 \pm 7.3$ & $46.1 \pm 16.2$ & $41.2 \pm 11.3$ & $0.13 \pm 0.02$ & $0.13 \pm 0.06$ & $0.11 \pm 0.03$ & $0.64 \pm 0.07$ & $0.42 \pm 0.07^{*}$ & $0.38 \pm 0.03^{*}$ \\
\hline GLOBAL Median \pm SD & $66.0 \pm 27$ & $71.0 \pm 25$ & $63.9 \pm 25$ & $\mathbf{0 . 1 3} \pm 0.02$ & $\mathbf{0 . 1 1} \pm 0.04$ & $\mathbf{0 . 1 0} \pm 0.02$ & $0.60 \pm 0.11$ & $\mathbf{0 . 4 3} \pm 0.08$ & $0.37 \pm 0.07^{*}$ \\
\hline
\end{tabular}

$H$ Hemoculture; $E$ Exudate; $S$ Sputum; $V$ Vaginal; $P$ Preservation liquid; (-): No data; $\left(^{*}\right) p<0.05$

mean $\mathrm{CSH}$ value of the strains, although the decrease was not statistically significant $(P>0.5)$.

Adhesion of yeast cells to polystyrene surface was evaluated by resuspending the cells in PBS. All the strains were highly adherent with an average OD of $0.13 \pm 0.02$ for both groups. Adherence capacity of C. glabrata incubated in the presence of subinhibitory concentrations of SEEP $(0.10$ and $0.05 \%)$ was not modified significantly with respect to the propolis-free control.

The C. glabrata biofilms were quantified at $24 \mathrm{~h}$ of culture in RPMI 1640 by XTT reduction. All the strains were biofilm-forming, with an average of $0.60 \pm 0.11$ (range 0.38 to 0.71). Biofilm-formation diminished with the different concentrations of propolis tested in a dose-dependent way; it was observed that as the concentrations increased, metabolic biofilm activity measured by XTT decreased, compared to controls without propolis and solvent control. The presence of $0.05 \%$ propolis diminished the biofilmformation to $0.43 \pm 0.08$ (range 0.31 to 0.55 ), and with $0.10 \%$ propolis to $0.37 \pm 0.07$ (range 0.29 to 0.45 ) in a statistically significant manner $\left(R^{2}=0.80 ; \quad P<0.05\right)$, with a more pronounced decrease in the group of moderately hydrophobic strains. This XTT-measured reduction indicates that propolis inhibits biofilmformation. As an example of biofilm reduction, Fig. 2

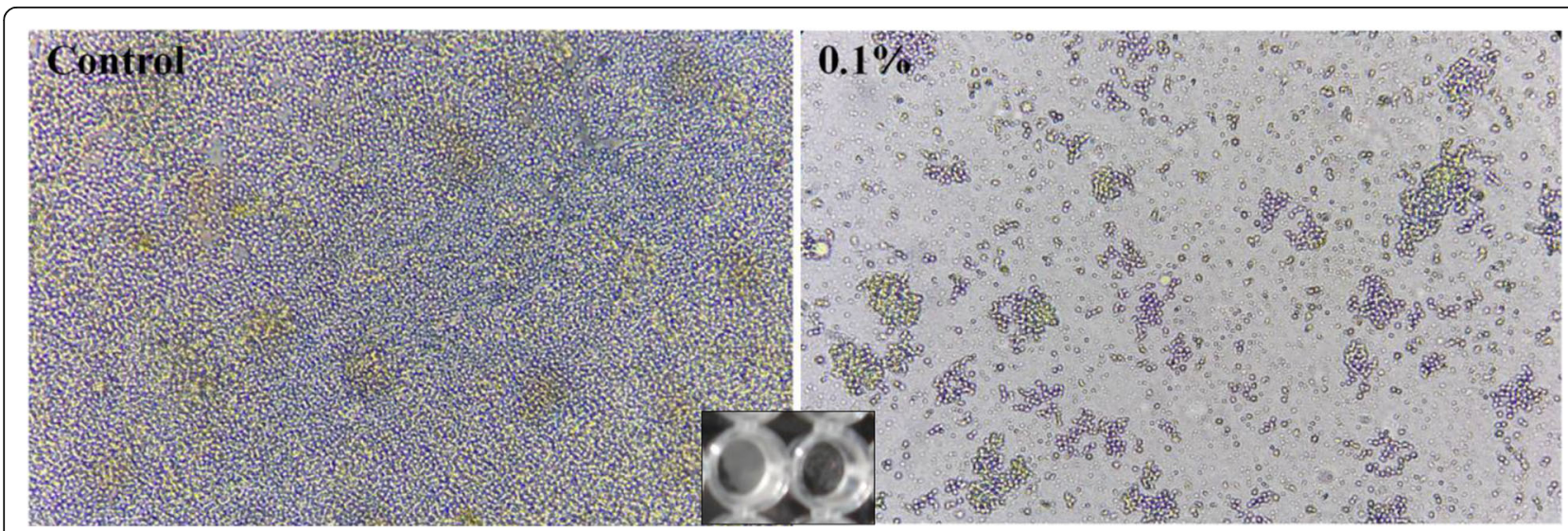

Fig. 2 Representative images of untreated (control) and SEEP-treated (0.1\%) of C. glabrata biofilm with inverted optical microscope $(\times 40)$ 
shows a representative biofilm generated by C. glabrata strain 30 compared to biofilm after treatment with $01 \%$ of SEEP.

\section{Discussion}

The incidence of infections by C. glabrata has risen in recent years due to increased use of fluconazole, and to an increase in the susceptible population, since this species is currently considered as an emergent pathogen. Drug-resistance ability of C. glabrata has been attributed to its haploid genome which permits it to undergo rapid genetic changes [33]. C. glabrata develops resistance during treatment or prophylaxis with fluconazole [7], and frequently acquires high level resistance crossed with triazoles, and also to equinocandines [34]. In the present study a high percentage of C. glabrata was resistant or had reduced susceptibility to fluconazole. Two strains presented crossed resistance with voriconazole, and one strain was resistant also to caspofungin and to amphotericin $\mathrm{B}$, antifungals to which the rest of the strains were sensitive. Resistance to traditional antifungals is becoming an important health problem, and is aggravated in infectious processes related to biofilmformation. There is a need to find therapeutic strategies by investigating existing products in natural environments which may have usefulness as therapeutic agents by inhibiting certain virulence factors [13, 35].

Concordant results exist on the fungistatic and fungicidal activity of propolis, although with variations in the findings related to the origin of the propolis, to the type of extract obtained and to the reading method used. Table 3 summarizes the antifungal activity of SEEP and other ethanolic extracts of propolis of different origins against C. glabrata. Only extracts from France [16] and Brazil [17] are reported to have a higher activity than SEEP. In relation to the methodology employed, the agar dilution method used in this work for MIC evaluation permitted very reliable readings by eliminating the turbidity produced by the propolis extract. Authors who have performed comparative studies have reported a good correlation with the CLSI reference method by microdilution [36, 37]. Some authors such as Sweda et al. [21] and Gucwa et al. [26] who used the microdilution method in broth (Table 3), did not read the MIC by propolis sedimentation, obtaining only the MFC values.

The growth kinetics of C. glabrata in the presence of $0.2 \%(120 \mu \mathrm{g} / \mathrm{mL})$ shows a long lag phase. There is a significant decrease in the exponential phase growth rate and a very low biomass yield in the stationary phase. SEEP, at the MIC dose, produced a strong inhibition of the planktonic growth of C. glabrata.

Antifungal capacity of propolis extract in vitro is influenced by its chemical variation, due to the geographical location of the collection site and to the diverse plant origins of propolis, as has been demonstrated in several studies [18, 38, 39]. The main components of propolis are flavonoids, fatty acids and aromatic acids [40]. This new SEEP contains high amounts of polyphenols and a detailed analysis of its chemical composition revealed the presence of compounds found in commercial virgin olive oils such as Ferulic acid, Vanillic acid, 1Acetoxypinoresinol (lignan), p-HPEA-EA (ligstroside derivative) and 3,4-DHPEA-EA (oleuperin derivative), and Vanillin (phenolic aldehyde) [41, 42]. Notably, Vanillic acid, 1-Acetoxypinoresinol, p-HPEA-EA and 3,4DHPEA-EDA have never been detected before in propolis samples.

Several studies have attributed the antimicrobial activity of propolis to the presence of specific flavonoids and phenolic acids, such as galangin, pinocembrin, pinostrobin as well as ferulic and caffeic acids [43-45]. However, a recent study has shown that the SEEP used in this study does not contain any of the above-mentioned flavonoid agents (except for ferulic acid), and yet show similar or higher antimicrobial activity than the propolis samples that contain them. In particular, newly identified compounds in SEEP (i.e. Vanillic acid, 1Acetoxypinoresinol, p-HPEA-EA and 3,4-DHPEA-EDA), also present in olive oil and known to possess antimicrobial properties, were proposed to be potentially responsible for the detected antifugicidal properties of SEEP [22]. In addition, it has been previously suggested that

Table 3 Antifungal activity of ethanolic extract of propolis from different geographical origins against Candida glabrata strains

\begin{tabular}{|c|c|c|c|c|c|}
\hline Candida glabrata (n) & Propolis origin & Range MIC $(\mu \mathrm{g} / \mathrm{ml}$ or $\% \mathrm{v} / \mathrm{v})$ & Range MFC $(\mu \mathrm{g} / \mathrm{ml}$ or $\% \mathrm{v} / \mathrm{v})$ & MIC Methodology & References \\
\hline 12 & Spain & $60-240(0.1-0.4 \%)$ & $240-480(0.4-0.8 \%)$ & Agar dilution $^{a}$ & Present work \\
\hline 1 & France * & $15.63-31.25$ & - & Microdilution in broth ${ }^{b}$ & Boisard et al. [16] \\
\hline 14 & Poland * & - & $1.25->5 \%$ & & Szweda et al. [21] \\
\hline 1 & Poland * & - & $0.31->2.5 \%$ & & Gucwa et al. [26] \\
\hline 14 & Iran & $250-5000$ & $250-8000$ & Microdilution in broth ${ }^{b}$ & Shokri et al. [19] \\
\hline 1 & Brazil & 64 & 256 & Microdilution in broth ${ }^{\text {a }}$ & Siqueira et al. [20] \\
\hline 1 & Brazil $^{*}$ & 7.8 & 250 & Microdilution in broth $^{a}$ & Freires et al. [17] \\
\hline
\end{tabular}

MIC minimum inhibitory concentration; MFC minimum fungicidal concentration by microdilution in broth and subculture on agar in all studies; $\left({ }^{*}\right)$ several propolis samples; $(-)$ No data; $\left({ }^{a}\right) 100 \%$ inhibition of growth; $\left({ }^{b}\right) 80 \%$ reduction of growth 
the antifungal activity of propolis is associated with the presence of the isoflavone formononetin [46], a compound that is also present in SEEP [22]. Similarly, these olive oil phenolic compounds may also contribute with their protective action in diverse diseases to healthy organisms [47, 48]. Specifically, these compounds may have protective effects against infectious, neurodegenerative or cardiovascular diseases, amongst others. Additionally, relatively high amounts of ferulic acid and quercetin were distinguished, both known for their important therapeutic benefits $[49,50]$.

Pippi et al. [51] carried out a comparative study of the effect of benzophenone enriched fraction obtained from Brazilian red propolis (BZP-BRP) on strains of C. glabrata resistant to traditional antifungal agents, and found that the strains resistant to fluconazole had good sensitivity to propolis. In our study, we obtained a similar result; the C. glabrata strains studied had low sensitivity to fluconazole, and were sensitive to propolis. The multiresistant strain was sensitive to propolis extract, and only strain 12 , resistant to fluconazole and voriconazole, showed greater resistance to propolis than the rest of the strains.

Most strains of C. glabrata have a marked hydrophobic character and high levels of adherence. Tomičić et al. [52] studied CSH with a similar protocol to that used in our study (MATH) and evaluated adherence capacity on microplates, performing the reading by staining with crystal violet. Although it is difficult to compare results when there is no standardization of protocols, there are coincident findings. CSH and adherence are closely related, but linearity between them was not obtained due to the saturation that exists in adherence capacity, as can be observed in our previous study on Candida tropicalis [31]. Based on the results obtained, the effect on CHS is not clear. The two resistant strains had different characteristics: both had been isolated from blood cultures but with respect to some virulence factors, they did not show uniformity. Multi-resistant strain 30 had medium levels of $\mathrm{CSH}$ and formed a large biofilm, while strain 12 was highly hydrophobic with a lower degree of biofilm production. This data, in accordance with previous studies, indicates that CSH does not correlate with the production of biofilms [31]. There is no evident tendency of what the effect of propolis is on the yeast surface, and in this sense, even though the subinhibitory concentrations seem to reduce adhesion of the yeast to polystyrene, it is not statistically significant.

Biofilm-forming capacity is an important resistance factor of C. glabrata since it contributes to the persistence of the microorganism inside the host. Biofilm formation has important clinical repercussions, and it begins with adherence to a substrate, which is related to $\mathrm{CSH}[8,31]$. The strains of C. glabrata studied are biofilm-forming but at a lower level than other species with filament capacity such as C. albicans and C. tropicalis [31]. Kucharíková et al. [53], in their studies on biofilm formation of C. glabrata using a method similar to the one used in our study, i.e. XTT reduction in 96-well polystyrene microplates and in RPMI-1640 at $\mathrm{pH} 7$, obtained similar findings to ours in the control. Currently, there is widespread interest in the elucidation of matrix components, their function and their modulation by the host environment to unveil their role in the pathogenesis of C. glabrata [54]. These findings are crucial for the development of new therapies to prevent or eradicate $C$. glabrata biofilms. Inhibition of biofilm-formation of $C$. glabrata in the presence of propolis has been scarcely studied. In our work, we found that subinhibitory concentrations of propolis extract significantly reduce the biofilm formed by $C$. glabrata in a dose- dependent manner, without affecting other virulence-related factors such as CSH or adherence capacity.

Although the antifungal activity of propolis has been widely studied, the mechanism of action on eukaryotic cells remains unclear. Authors such as Gucwa et al. [26] suggest that the cell wall cannot be considered the target of an ethanolic extract of propolis from Poland, indicating the fungal cell membrane as the most probable site of action. In our study, biofilm formation was significantly inhibited by SEEP in a similar way to the inhibition produced in the growth of planktonic cells, while adhesion capacity and CSH were not significantly affected. This suggests, according to Gucwa et al. [26], that propolis affects yeast without impacting the cell wall, which is responsible for its hydrophobic nature and directly related to adherence capacity. Conversely, propolis affects biofilm formation by inhibiting yeast growth. This is also corroborated by the effectiveness of propolis against azole-resistant strains [19-21, 26], which act by altering the cell wall. If the antifungal compounds of propolis do not target the cell wall, the mechanisms of azole resistance do not influence their effectiveness.

Other authors such as Okińczyc et al. studied the effect of a Nepalese propolis on C. albicans filamentation and oxidative stress [55]. Propolis inhibited filamentation, causing a reduction in virulence because the cells became less hydrophobic. In our study, the CSH of $C$. glabrata was not affected, probably because they do not filament and unlike C. albicans, their yeast-like form is hydrophobic. Furthermore, they observed that propolis caused oxidative stress through the production of the superoxide anion radical $\left(\mathrm{O}_{2}{ }^{--}\right)$and a lower concentration of the hydroxyl radical $\left(\mathrm{OH}^{*}\right)$, suggesting that indirect generation of reactive oxygen species (ROS) may be the result of different processes such as disruption cell membranes. 
In a previous work on the physicochemical modifications of the cell surface of bacteria by SEEP [23], we proposed that the mechanism of action of propolis against bacteria appears to be initially physical, with structural damage to the bacterial cell membrane/wall. This is a mechanism of action to which microorganisms may find it difficult to generate resistance, especially if different propolis molecules interact synergistically. Further research is needed in order to clarify the mechanism of the antifungal and antibiofilm activity of propolis in yeast. The rise in infections by C. glabrata and its resistance to antifungals, in particular azoles, and the fact that a large number of recalcitrant infections are related with biofilm production, point to the need for research studies to develop alternative therapies with natural products as propolis which complement traditional treatments.

\section{Conclusion}

The novel Spanish ethanolic extract of propolis demonstrated a capacity against $C$. glabrata. In addition to its antifungal potential, SEEP reduced biofilm formation of this emergent opportunistic pathogen. This anti-biofilm activity makes it an interesting therapeutic alternative in the prevention and control of biodevice-associated infections. Future research with biomaterial coatings with SEEP could be explored to strengthen their possible use on prostheses.

\section{Abbreviations \\ CFU/mL: Colony forming units per milliliter; CSH: Cell surface hydrophobicity; Eq: Equivalent; MFC: Minimum fungicidal concentration; MIC: Minimum inhibitory concentration; PBS: Phosphate-buffered saline; SEEP: Spanish ethanolic extract of propolis; XTT: 2,3-bis (2-methoxy-4-nitro-5-sulfophenyl)-5- [(phenylamino)carbonyl]-2H-tetrazolium hydroxide}

\section{Acknowledgements}

The authors thank Artesanos Virgen de Extremadura, S.L, Badajoz, España, for kindly providing the samples of propolis, J McCue for linguistic revision of the manuscript, and G Gómez-Landero for technical laboratory assistance.

\section{Authors' contributions}

MCFC and MTBB designed the study, supervised the experiments, inspected the data analyses, and revised the manuscript; LHG, CGN, RSS and LL performed the experiments, drafted the manuscript and performed data analysis; CPG funding acquisition, and revised the manuscript. All authors read and approved the final manuscript.

\section{Funding}

This research was supported by a Grant from the "Consejería de Economía e Infraestructuras, Junta de Extremadura" and "Fondo Europeo de Desarrollo Regional "Una Manera de Hacer Europa" (FEDER)" founds (IB16154, GR18096).

\section{Availability of data and materials}

The datasets used and analyzed during the current study are available from the corresponding author on reasonable request.

\section{Declarations}

Ethics approval and consent to participate

Not applicable.

\section{Consent for publication}

Not applicable.

\section{Competing interests}

The authors declare that they have no competing interest.

\section{Author details}

'Departamento de Ciencias Biomédicas, Área de Microbiología, Facultad de Medicina y Ciencias de la Salud, Universidad de Extremadura, Badajoz, Spain. ${ }^{2}$ Centro de Investigación Biomédica en Red de Bioingeniería, Biomateriales y Nanomedicina (CIBER BBN), Badajoz, Spain. Instituto Universitario de Investigación Sanitaria de Extremadura (INUBE), Badajoz, Spain. ${ }^{4}$ Servicio de Microbiología, Hospital Universitario de Badajoz, Badajoz, Spain. ${ }^{5}$ Laboratorio de Salud Pública (LSP), Hospital Universitario de Badajoz, Badajoz, Spain.

Received: 16 November 2020 Accepted: 13 May 2021

Published online: 21 May 2021

References

1. Álvez F, Figueras C, Roselló E. Infecciones fúngicas invasivas emergentes. Anales españoles de pediatría. 2010;73(1):52.

2. Bolotin-Fukuhara M, Fairhead C. Candida glabrata: a deadly companion? Yeast. 2014;31(8):279-88. https://doi.org/10.1002/yea.3019.

3. Schell WA, Jones AM, Borroto-Esoda K,Alexander BD. 2017. Antifungal activity of SCY-078 and standard antifungal agents against 178 clinical isolates of resistant and susceptible Candida species. Antimicrob Agents Chemother. 61:e01102-17. https://doi.org/10.1128/AAC.01102-17.

4. Vale-Silva LA, Sanglard D. Tipping the balance both ways: drug resistance and virulence in Candida glabrata. FEMS Yeast Res. 2015;15(4):fov025.

5. Diaz MC, Camponovo R, Araya I, Cerda A, Santander MP, Carrillo-Muñoz AJ. Identification and in vitro antifungal susceptibility of vaginal Candida spp. isolates to fluconazole, clotrimazole and nystatin. Rev Esp Quimioter. 2016; 29(3):151-4.

6. Henriques M, Williams D. Pathogenesis and Virulence of Candida albicans and Candida glabrata. Pathogens. 2020;9(9):752. https://doi.org/10.3390/pa thogens 9090752.

7. Silva S, Negri M, Henriques M, Oliveira R, Williams DW, Azeredo J. Candida glabrata, Candida parapsilosis and Candida tropicalis: biology, epidemiology, pathogenicity and antifungal resistance. FEMS Microbiol Rev. 2012;36(2): 288-305. https://doi.org/10.1111/j.1574-6976.2011.00278.x.

8. Blanco MT, Sacristán B, Lucio L, Blanco J, Pérez-Giraldo C, Cándido GómezGarcía A. La hidrofobicidad de la superficie celular como indicador de otros factores de virulencia en Candida albicans. Rev Iberoam Micol. 2010;27(4); 195-9. https://doi.org/10.1016/j.riam.2010.09.001.

9. Francolini I, Donelli G. Prevention and control of biofilm-based medicaldevice-related infections. FEMS Immunol Med Microbiol. 2010;59(3):227-38. https://doi.org/10.1111/j.1574-695X.2010.00665.x.

10. Kojic EM, Darouiche RO. Candida infections of medical devices. Clin Microbiol Rev. 2004;17(2):255-67. https://doi.org/10.1128/CMR.17.2.255-267.2 004.

11. Nobile CJ, Johnson AD. Candida albicans biofilms and human disease. Annu Rev Microbiol. 2015;69(1):71-92. https://doi.org/10.1146/annurev-micro-091 014-104330.

12. Mendoza-Juache A, Aranda-Romo S, Bermeo-Escalona JR, Gómez-Hernández A, Pozos-Guillén A, Sánchez-Vargas LO. The essential oil of Allium sativum as an alternative agent against Candida isolated from dental prostheses. Rev Iberoam Micol. 2017;34(3):158-64. https://doi.org/10.1016/j.riam.2016.11.008.

13. Xu K, Wang JL, Chu MP, Jia C. Activity of coumarin against Candida albicans biofilms. J Mycol Med. 2019;29(1):28-34. https://doi.org/10.1016/j.mycmed.2 018.12.003.

14. Crane E. In: Mizrahi A, Lensky Y, editors. The Past and Present Importance of Bee Products to Man, in Bee Products: Properties, Applications, and Apitherapy. Boston: Springer US; 1997. p. 1-13.

15. Sforcin JM. Biological properties and therapeutic applications of Propolis. Phytother Res. 2016;30(6):894-905. https://doi.org/10.1002/ptr.5605.

16. Boisard S, et al. Antifungal and antibacterial metabolites from a French poplar type propolis. Evid Based Complement Alternat Med. 2015;2015: 319240.

17. Freires IA, Queiroz VCPP, Furletti VF, Ikegaki M, de Alencar SM, Duarte MCT, et al. Chemical composition and antifungal potential of Brazilian propolis against Candida spp. J Mycol Med. 2016;26(2):122-32. https://doi.org/10.101 6/j.mycmed.2016.01.003.

18. Murad JM, Calvi SA, Soares AMVC, Bankova V, Sforcin JM. Effects of propolis from Brazil and Bulgaria on fungicidal activity of macrophages against 
Paracoccidioides brasiliensis. J Ethnopharmacol. 2002;79(3):331-4. https:// doi.org/10.1016/S0378-8741(01)00404-4.

19. Shokri H, Khosravi AR, Yalfani R. Antifungal efficacy of propolis against fluconazole-resistant Candida glabrata isolates obtained from women with recurrent vulvovaginal candidiasis. Int J Gynaecol Obstet. 2011;114(2):158-9. https://doi.org/10.1016/j.jpgo.2011.02.019.

20. Siqueira $A B$, et al. Antifungal activity of propolis against Candida species isolated from cases of chronic periodontitis. Braz Oral Res. 2015;29(1):1-6. https://doi.org/10.1590/1807-3107BOR-2015.vol29.0083.

21. Szweda P, Gucwa K, Kurzyk E, Romanowska E, Dzierżanowska-Fangrat K, Zielińska Jurek A, et al. Essential oils, silver nanoparticles and Propolis as alternative agents against fluconazole resistant Candida albicans, Candida glabrata and Candida krusei clinical isolates. Indian J Microbiol. 2015;55(2): 175-83. https://doi.org/10.1007/s12088-014-0508-2.

22. Fernández-Calderón MC, Navarro-Pérez ML, Blanco-Roca MT, Gómez-Navia C, Pérez-Giraldo C, Vadillo-Rodríguez V. Chemical Profile and Antibacterial Activity of a Novel Spanish Propolis with New Polyphenols also Found in Olive Oil and High Amounts of Flavonoids. Molecules. 2020;25(15):3318; https://doi.org/10.3390/molecules25153318.

23. Vadillo-Rodríguez V, Cavagnola MA, Pérez-Giraldo C, Fernández-Calderón MC. A physico-chemical study of the interaction of ethanolic extracts of propolis with bacterial cells. Colloids Surf B: Biointerfaces. 2021;200:111571. https://doi.org/10.1016/j.colsurfb.2021.111571.

24. Wiegand I, Hilpert K, Hancock RE. Agar and broth dilution methods to determine the minimal inhibitory concentration (MIC) of antimicrobial substances. Nat Protoc. 2008;3(2):163-75. https://doi.org/10.1038/nprot.2007.521.

25. CLSI. Reference method for broth dilution antifungal susceptibility testing of yeasts - fourth edition. CLSI document M27-A4. Wayne: Clinical and Laboratory Standards Institute; 2017.

26. Gucwa K, Kusznierewicz B. Antifungal Activity and Synergism with Azoles of Polish Propolis. Pathogens. 2018;7(2):56; https://doi.org/10.3390/pa thogens7020056.

27. Blanco MT, Falcón MA, Chordi A. Interaction established between Staphylococcus aureus and Pseudomonas aeruginosa when they are cultivated together in a semi-synthetic medium. Microbiol Esp. 1982;35:33-41.

28. Molina MR, Rodríguez AC. Determinación de la curva de crecimiento microbiano Saccharomyces Boulardii en Tunta variedades Chaska y Negra; 2019.

29. Ramage G, Vande Walle K, Wickes BL, López-Ribot J́L. Standardized method for in vitro antifungal susceptibility testing of Candida albicans biofilms. Antimicrob Agents Chemother. 2001;45(9):2475-9. https://doi.org/10.112 8/AAC.45.9.2475-2479.2001.

30. Blanco MT, Morales JJ, Lucio L, Pérez-Giraldo C, Hurtado C, Gómez-García AC. Modification of adherence to plastic and to human buccal cells of Candida albicans and Candida dubliniensis by a subinhibitory concentration of itraconazole. Oral Microbiol Immunol. 2006;21(1):69-72. https://doi.org/1 0.1111/j.1399-302X.2005.00260.x.

31. Galán-Ladero MA, Blanco-Blanco MT, Hurtado C, Pérez-Giraldo C, Blanco MT, Gómez-García AC. Determination of biofilm production by Candida tropicalis isolated from hospitalized patients and its relation to cellular surface hydrophobicity, plastic adherence and filamentation ability. Yeast. 2013:30(9):331-9. https://doi.org/10.1002/yea.2965.

32. Rosenberg M, Gutnick D, Rosenberg E. Adherence of bacteria to hydrocarbons: a simple method for measuring cell-surface hydrophobicity. FEMS Microbiol Lett. 1980;9(1):29-33. https://doi.org/10.1111/j.1574-6968.1 980.tb05599.x

33. Whaley SG, Rogers PD. Azole Resistance in Candida glabrata. Curr Infect Dis Rep. 2016;18(12):41. https://doi.org/10.1007/s11908-016-0554-5.

34. Biswas C, Chen SCA, Halliday C, Martinez E, Rockett RJ, Wang Q, et al. Whole Genome Sequencing of Candida glabrata for Detection of Markers of Antifungal Drug Resistance. J. Vis. Exp. 2017;(130):e56714, https://doi.org/1 $0.3791 / 56714$.

35. Haghdoost NS, Salehi TZ, Khosravi A, Sharifzadeh A. Antifungal activity and influence of propolis against germ tube formation as a critical virulence attribute by clinical isolates of Candida albicans. J Mycol Med. 2016;26(4): 298-305. https://doi.org/10.1016/..mycmed.2015.11.004.

36. Castro Méndez C, Sánchez EG, Martín-Mazuelos E. Updating of in vitro antifungal susceptibility tests. Enferm Infecc Microbiol Clin. 2019;37(Suppl 1): 32-9.

37. Arikan S. Current status of antifungal susceptibility testing methods. Med Mycol. 2007:45(7):569-87. https://doi.org/10.1080/13693780701436794.
38. Dalben-Dota KF, Faria MGI, Bruschi ML, Pelloso SM, Lopes-Consolaro ME, Svidzinski TIE. Antifungal activity of propolis extract against yeasts isolated from vaginal exudates. J Altern Complement Med. 2010;16(3):285-90. https://doi.org/10.1089/acm.2009.0281.

39. Ota C, Unterkircher C, Fantinato V, Shimizu MT. Antifungal activity of propolis on different species of Candida. Mycoses. 2001;44(9-10):375-8. https://doi.org/10.1046/j.1439-0507.2001.00671.x.

40. Silici $\mathrm{S}, \mathrm{Koc}$ AN. Comparative study of in vitro methods to analyse the antifungal activity of propolis against yeasts isolated from patients with superficial mycoses. Lett Appl Microbiol. 2006;43(3):318-24. https://doi.org/1 0.1111/j.1472-765X.2006.01949.X.

41. Brenes M, García A, García P, Rios JJ, Garrido A. Phenolic compounds in Spanish olive oils. J Agric Food Chem. 1999;47(9):3535-40. https://doi.org/1 0.1021/j990009o.

42. García-Martínez O, de Luna-Bertos E, Ramos-Torrecillas J, Ruiz C, Milia E, Lorenzo ML, et al. Phenolic compounds in extra virgin olive oil stimulate human Osteoblastic cell proliferation. PLoS One. 2016;11(3):e0150045. https://doi.org/10.1371/journal.pone.0150045.

43. Isla MI, Paredes-Guzman JF, Nieva-Moreno MI, Koo H, Park YK. Some chemical composition and biological Activity of northern argentine Propolis. J Agric Food Chem. 2005;53(4):1 166-72. https://doi.org/10.1021/jf040130h.

44. Park YK, et al. Antimicrobial activity of propolis on oral microorganisms. Curr Microbiol. 1998;36(1):24-8. https://doi.org/10.1007/s002849900274.

45. Afrouzan H, Tahghighi A, Zakeri S, Es-haghi A. Chemical composition and antimicrobial activities of Iranian Propolis. Iran Biomed J. 2018;22(1):50-65. https://doi.org/10.22034/ibj.22.1.50

46. das Neves MVM, et al. Isoflavone formononetin from red propolis acts as a fungicide against Candida sp. Brazil J Microbiol. 2016;47(1):159-66.

47. Owen RW, Giacosa A, Hull WE, Haubner R, Spiegelhalder B, Bartsch H. The antioxidant/anticancer potential of phenolic compounds isolated from olive oil. Eur J Cancer. 2000;36(10):1235-47. https://doi.org/10.1016/50959-804 9(00)00103-9.

48. Karaosmanoglu H, Soyer F, Ozen B, Tokatli F. Antimicrobial and antioxidant activities of Turkish extra virgin olive oils. J Agric Food Chem. 2010;58(14): 8238-45. https://doi.org/10.1021/jf1012105.

49. Zhao Z, Moghadasian MH. Chemistry, natural sources, dietary intake and pharmacokinetic properties of ferulic acid: a review. Food Chem. 2008; 109(4):691-702. https://doi.org/10.1016/j.foodchem.2008.02.039.

50. Shaik YB, Castellani ML, Perrella A, Conti F, Salini V, Tete S, et al. Role of quercetin (a natural herbal compound) in allergy and inflammation. J Biol Regul Homeost Agents. 2006;20(3-4):47-52.

51. Pippi B, Lana AJD, Moraes RC, Güez CM, Machado M, de Oliveira LFS, et al. In vitro evaluation of the acquisition of resistance, antifungal activity and synergism of Brazilian red propolis with antifungal drugs on Candida spp. J Appl Microbiol. 2015;1 18(4):839-50. https://doi.org/10.1111/jam.12746.

52. Tomičić Z, Zupan J, Matos T, Raspor P. Probiotic yeast Saccharomyces boulardii (nom. Nud.) modulates adhesive properties of Candida glabrata. Med Mycol. 2016;54(8):835-45. https://doi.org/10.1093/mmy/myw026.

53. Kucharíková S, Tournu H, Lagrou K, van Dijck P, Bujdáková H. Detailed comparison of Candida albicans and Candida glabrata biofilms under different conditions and their susceptibility to caspofungin and anidulafungin. J Med Microbiol. 2011;60(Pt 9):1261-9. https://doi.org/10.1 099/jmm.0.032037-0.

54. Gonçalves B, Azevedo N, Osório H, Henriques M, Silva S. Revealing Candida glabrata biofilm matrix proteome: global characterization and $\mathrm{pH}$ response. Biochem J. 2021;478(4):961-74. https://doi.org/10.1042/BCJ20200844.

55. Okińczyc P, Paluch E, Franiczek R, Widelski J, Wojtanowski KK, Mroczek T, et al. Antimicrobial activity of Apis mellifera L. and Trigona sp. propolis from Nepal and its phytochemical analysis. Biomed Pharmacother. 2020;129: 110435. https://doi.org/10.1016/j.biopha.2020.110435.

\section{Publisher's Note}

Springer Nature remains neutral with regard to jurisdictional claims in published maps and institutional affiliations. 